\title{
QUALITY IMPROVEMENT Improving the quality of discharge summaries through a direct feedback system
}

\author{
Authors: Charles H Earnshaw, ${ }^{\mathrm{A}}$ Amanda Pedersen, ${ }^{\mathrm{A}}$ Jo Evans, ${ }^{\mathrm{B}}$ Tina Cross, ${ }^{\mathrm{A}}$ Olivier Gaillemin ${ }^{\mathrm{C}}$ and \\ Arturo Vilches-Moraga ${ }^{\mathrm{C}}$
}

\section{Introduction}

There is a recognised need to improve the quality of discharge documentation to facilitate the safe and effective ongoing care of patients once they leave hospital. Previous studies have focused on individual interventions, such as teaching or feedback. Our continuous quality improvement project aims to improve the quality of discharge documentation at our hospital by providing a comprehensive overhaul of the education and feedback around discharge documentation.

\section{Methods}

We designed a comprehensive data analysis tool to analyse the performance of our discharge summaries. We presented at clinical governance sessions and arranged numerous teaching sessions for junior doctors. We developed a livefeedback system based on the content of a sample set of the previous month's summaries, which included poster-based feedback and group teaching.

Results

Our interventions have significantly improved the quality of our discharge documentation across a broad range of categories, including the summary of the stay, actions for general practitioners and information given to patients in lay terminology.

\section{Conclusion}

Our comprehensive quality improvement project has improved the quality of our discharge documentation. Further work aims to expand this project into a regional setting, as well as designing a strategy to maintain engagement of key stakeholders to ensure continued progress.

KEYWORDS: Safety, communication, care transition, quality improvement, discharge summary

DOI: 10.7861/fhj.2019-0046

Authors: ${ }^{\text {A }}$ physician, Salford Royal NHS Foundation Trust, Salford, UK; ${ }^{B}$ senior improvement advisor, Salford Royal NHS Foundation Trust, Salford, UK; ' ${ }^{\text {C }}$ Consultant physician, Salford Royal NHS Foundation Trust, Salford, UK

\section{Introduction}

Accurate discharge summary documentation plays a crucial role in the continuing healthcare of patients discharged from hospital. The Academy of Medical Royal Colleges (AoMRC) provides guidance on the structure and content of discharge summaries. ${ }^{1}$ Examples of content required, as specified by the AoMRC, include a social and functional assessment, a list of new diagnoses, details of the patient's past medical history (PMH) and information regarding any changes to prescribed medications. This information is critically important to allow the patient's ongoing health needs to be met by their general practitioner (GP) upon discharge back to the community.

If all of the required information is included, then this clearly has the potential to optimise the transition of care from hospital to home. Accurate discharge summaries also improve the followup of results of tests pending at discharge. ${ }^{2}$ Moreover, accurate discharge documentation can allow for large epidemiological studies to be performed (in healthcare systems set up to optimise usage of these documents). ${ }^{3-5}$ Conversely, poor quality discharge summaries carry increased risks of a number of medical errors, including medication prescription errors and delays in outpatient reviews. $^{6-9}$

We identified that there was an unmet need for improvement in the quality of our trust's discharge summaries. A broad and high impact quality improvement project (QIP) was therefore designed which had the goal of integrating both larger teaching sessions and more personalised feedback approaches, as well as testing additional strategies that we designed using a plan, do, study, act (PDSA) approach. This QIP therefore had the ambitious goal of implementing a wide series of interventions, in a controlled manner, to improve the quality of discharge summaries at our trust for patients over the age of 75 years.

\section{Methods}

In order to identify the key areas of discharge documentation that required improvement, a survey of 111 consultant clinicians and GPs working in the local area was performed. Forty of these clinicians were invited to participate in a rapid improvement event (RIE) using LEAN methodology to gain a full understanding of the process and the key issues and information required upon patient discharge from hospital. ${ }^{10}$ This allowed the key value-added elements of the discharge documentation to be identified. 
Table 1. The 38-point data collection tool, used when reviewing discharge summaries

\begin{tabular}{|c|c|c|c|c|c|c|}
\hline Demographic & Clinical summary & $\begin{array}{l}\text { Functional } \\
\text { assessment }\end{array}$ & $\begin{array}{l}\text { Medication } \\
\text { changes }\end{array}$ & Follow-up & $\begin{array}{l}\text { Acute kidney } \\
\text { injury }\end{array}$ & $\begin{array}{l}\text { Dementia/ } \\
\text { delirium }\end{array}$ \\
\hline Hospital number & $\begin{array}{l}\text { Past medical } \\
\text { history }\end{array}$ & $\begin{array}{l}\text { Documented if } \\
\text { from nursing or } \\
\text { residential home }\end{array}$ & New medications & $\begin{array}{l}\text { Is follow-up } \\
\text { required }\end{array}$ & $\begin{array}{l}\text { Did acute } \\
\text { kidney injury } \\
\text { occur }\end{array}$ & $\begin{array}{l}\text { Diagnosis of } \\
\text { delirium during } \\
\text { admission }\end{array}$ \\
\hline Ward & $\begin{array}{l}\text { Concise summary } \\
\text { of admission }\end{array}$ & $\begin{array}{l}\text { Changes to } \\
\text { functional status } \\
\text { documented }\end{array}$ & $\begin{array}{l}\text { If so: name, dose } \\
\text { and timing }\end{array}$ & $\begin{array}{l}\text { If so: included } \\
\text { in summary }\end{array}$ & $\begin{array}{l}\text { If so: stage } \\
\text { documented }\end{array}$ & $\begin{array}{l}\text { If so: recorded } \\
\text { on summary }\end{array}$ \\
\hline Consultant & $\begin{array}{l}\text { Relevant tests and } \\
\text { results }\end{array}$ & & If so: indication & $\begin{array}{l}\text { General } \\
\text { practitioner } \\
\text { action required }\end{array}$ & $\begin{array}{l}\text { If so: post- } \\
\text { discharge } \\
\text { monitoring }\end{array}$ & $\begin{array}{l}\text { Pre-existing } \\
\text { diagnosis of } \\
\text { dementia }\end{array}$ \\
\hline Age & $\begin{array}{l}\text { List of diagnoses } \\
\text { clearly stated }\end{array}$ & & $\begin{array}{l}\text { Medications } \\
\text { stopped }\end{array}$ & $\begin{array}{l}\text { If so: clear } \\
\text { instructions }\end{array}$ & & $\begin{array}{l}\text { If so: recorded } \\
\text { on summary }\end{array}$ \\
\hline Sex & & & If so: name & $\begin{array}{l}\text { Information in } \\
\text { lay terminology }\end{array}$ & & \\
\hline Admission date & & & If so: indication & & & \\
\hline Discharge date & & & Dose changes & & & \\
\hline $\begin{array}{l}\text { Grade of clinician } \\
\text { writing summary }\end{array}$ & & & If so: included & & & \\
\hline Multiple authors & & & If so: indication & & & \\
\hline Prepared in advance & & & $\begin{array}{l}\text { Allergy status } \\
\text { updated }\end{array}$ & & & \\
\hline
\end{tabular}

The findings from this event were integrated with the AoMRC guidelines and a six-category data collection tool was designed, with 38 total data points collected for each summary. The categories included clinical summary, functional assessment, medication changes, follow-up actions, acute kidney injury and dementia/ delirium, and are shown in detail in Table 1. Each individual point was graded in terms of the quality of the information included (not just whether it was present or absent) on a four-point scale from 'absent' to 'great'. This was then used to assess the overall quality of the summary, which is depicted in the figures throughout this paper. A baseline audit of 482 discharge summaries was performed in patients aged 75 years and over to assess trust-wide performance against the criteria identified in the survey. This specific cohort of patients was chosen for a number of reasons: older people are more likely to have complex care needs with multiple comorbidities, polypharmacy and multidisciplinary team requirements; they have increased readmission rates in our trust, as they do nationally, and it was hypothesised that high-quality discharge summaries may alleviate some of these problems. ${ }^{11,12}$

A series of interventions, based on the results of a survey of clinicians' understanding of discharge summary purpose and quality markers, were then designed. This included year-wide teaching of first-year doctors, induction training for doctors at the beginning of each new rotation and regular departmental teaching that aimed to improve the quality of our discharge summaries. The project was presented to the different specialties involved at their respective clinical governance meetings to increase awareness of the project. Participating departments included orthogeriatrics, the emergency assessment unit, the acute surgical unit and elderly medicine. A local project lead was identified within each department who collected monthly data from a sample of discharge documentation from that ward, and who was able to design interventions tailored to their specific department.

A novel live-feedback system was then designed, using a PDSA approach, to help facilitate the desired improvements. Forty discharge summaries were analysed on a monthly basis (with one clinician in each of the previously mentioned clinical departments responsible for reviewing discharge summaries; who remained the same from month to month, with the exception of rare occasions when they would rotate out of the trust due to clinical rotations). This clinician then fed the results back directly to the doctors completing the summaries. A poster was designed, also using a PDSA approach, to display feedback of a selection of discharge summaries from the previous month. Posters were updated with the strengths and weaknesses of the previous month, along with suggestions for improvement, and then displayed in a prominent location in the relevant clinical area. Awards for "discharge champions' (doctors or areas that have shown major improvement in the quality of discharge summaries) were created, which improved junior doctor engagement with the project.

The first monthly cycle was completed in November 2017, which allowed interim analysis of whether the induction and year-wide training sessions had made improvement in the quality of the discharge summaries to be performed. The live-feedback approach went live in February 2018 and was performed on a monthly basis.

\section{Results}

The aim of the project, the key strategic areas identified, along with the people involved and interventions performed are illustrated in a driver diagram (Fig 1). 


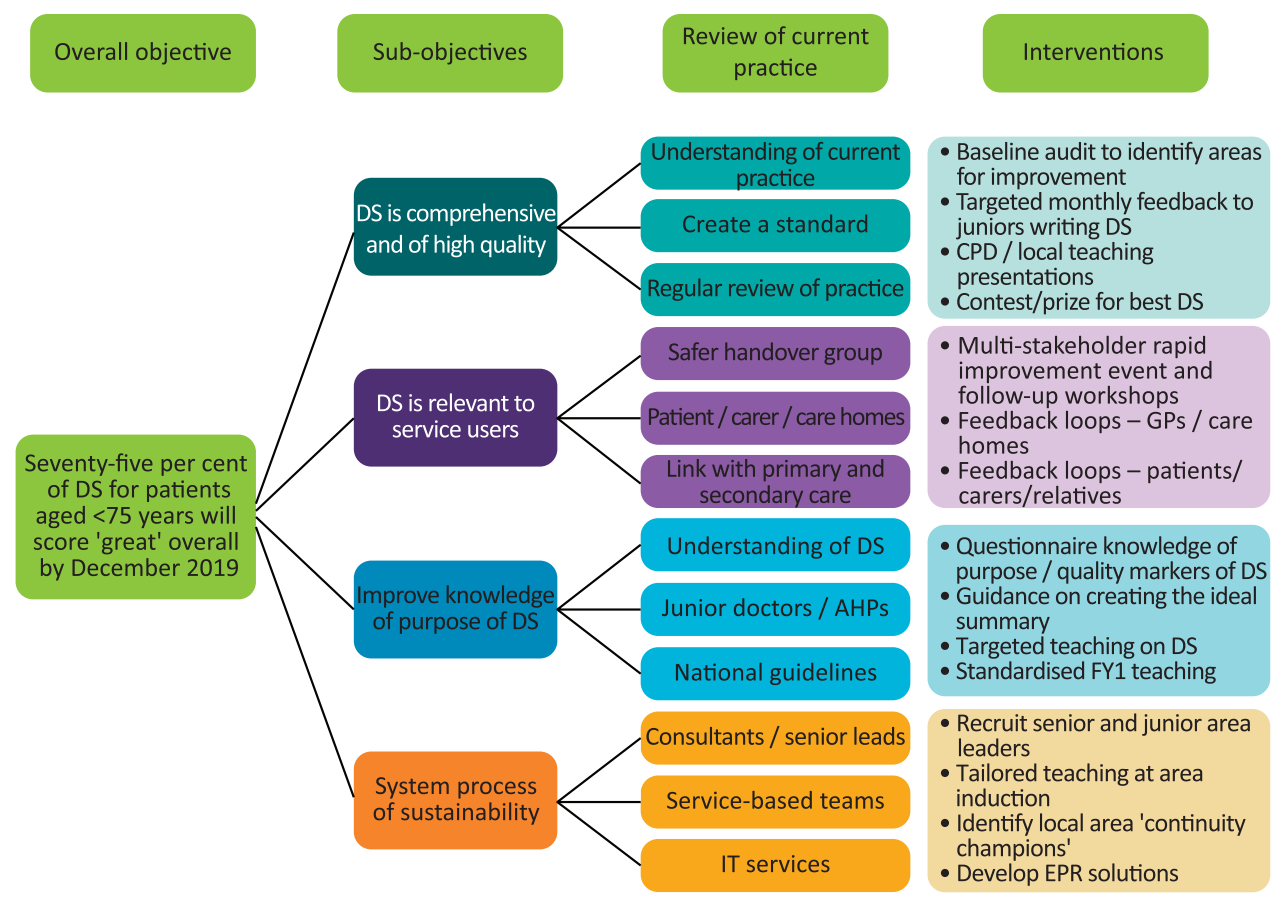

Fig 1. Driver diagram developed following rapid improvement event. AHPs $=$ allied healthcare professionals; $\mathrm{CPD}=$ continuing professional development; $\mathrm{DS}=$ discharge summaries; $E P R=$ electronic patient records; $F Y 1=$ foundation year-1 doctor; GP = general practitioner.

The findings from the RIE survey identified six key areas, around which the data collection tool was designed (previously described). Several aspects of the discharge summaries analysed in a baseline audit ( 482 summaries across seven wards) were recorded poorly. Specifically, this included documentation of follow-up actions required of the GP, a clinical summary of the patient's stay and information provided to the patient in lay terminology.

Fig 2 shows the number of discharge summaries completed to a 'good' standard (as defined in the data collection tool). In addition, the figure is annotated with different interventions performed throughout the project.

Fig 3 shows a breakdown of performance in several specific areas. Substantial improvements in the clinical summary (Fig 3a; increased from $29 \%$ to $47 \%$ ) and in the quality of information provided to the patient in lay terminology (Fig $3 \mathrm{~b}$; increased from $15 \%$ to $64 \%$ ) were observed. However, other areas require further improvement, including improving the communication of the patient's functional assessment, a key area identified by GPs, care home staff and community therapy teams.

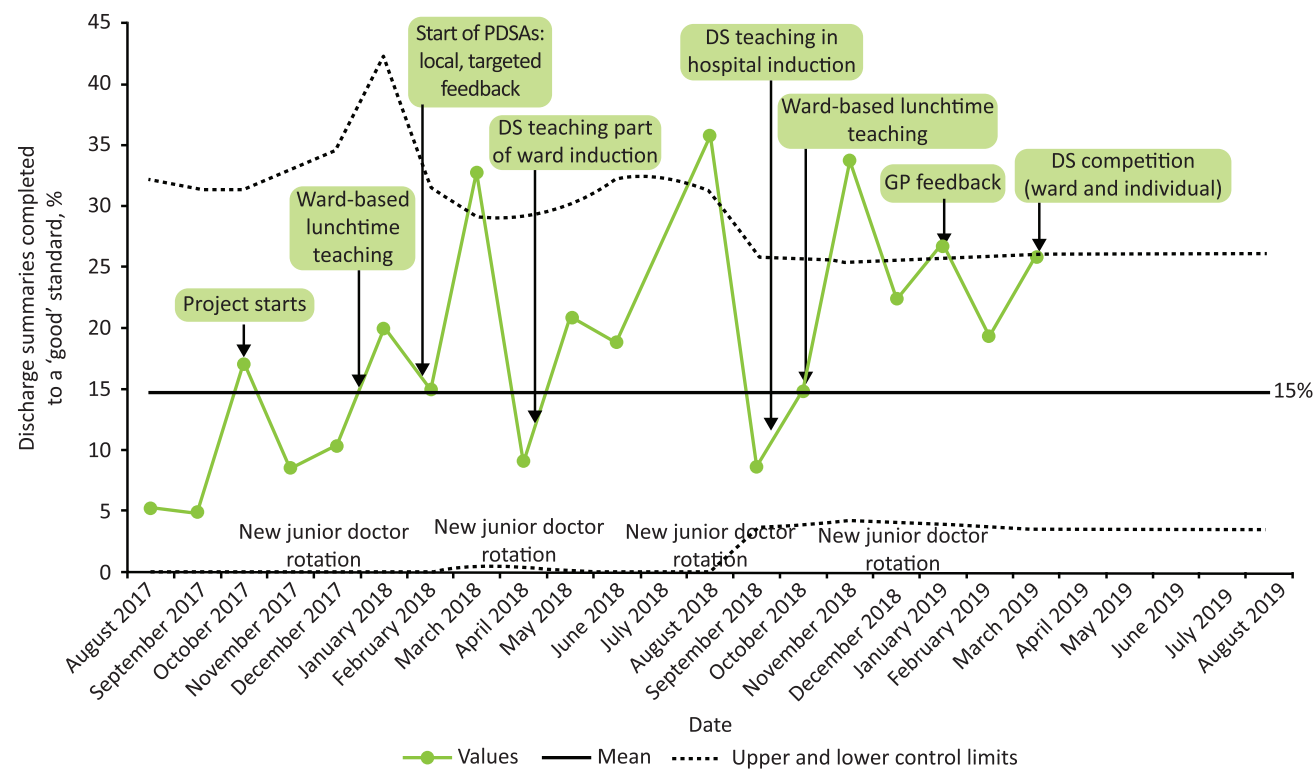

Fig 2. Proportion of discharge summaries completed to a 'good' standard and interventions performed throughout the project. DS = discharge summaries; $\mathrm{GP}=$ general practitioner; PDSA = plan, do, study, act. 

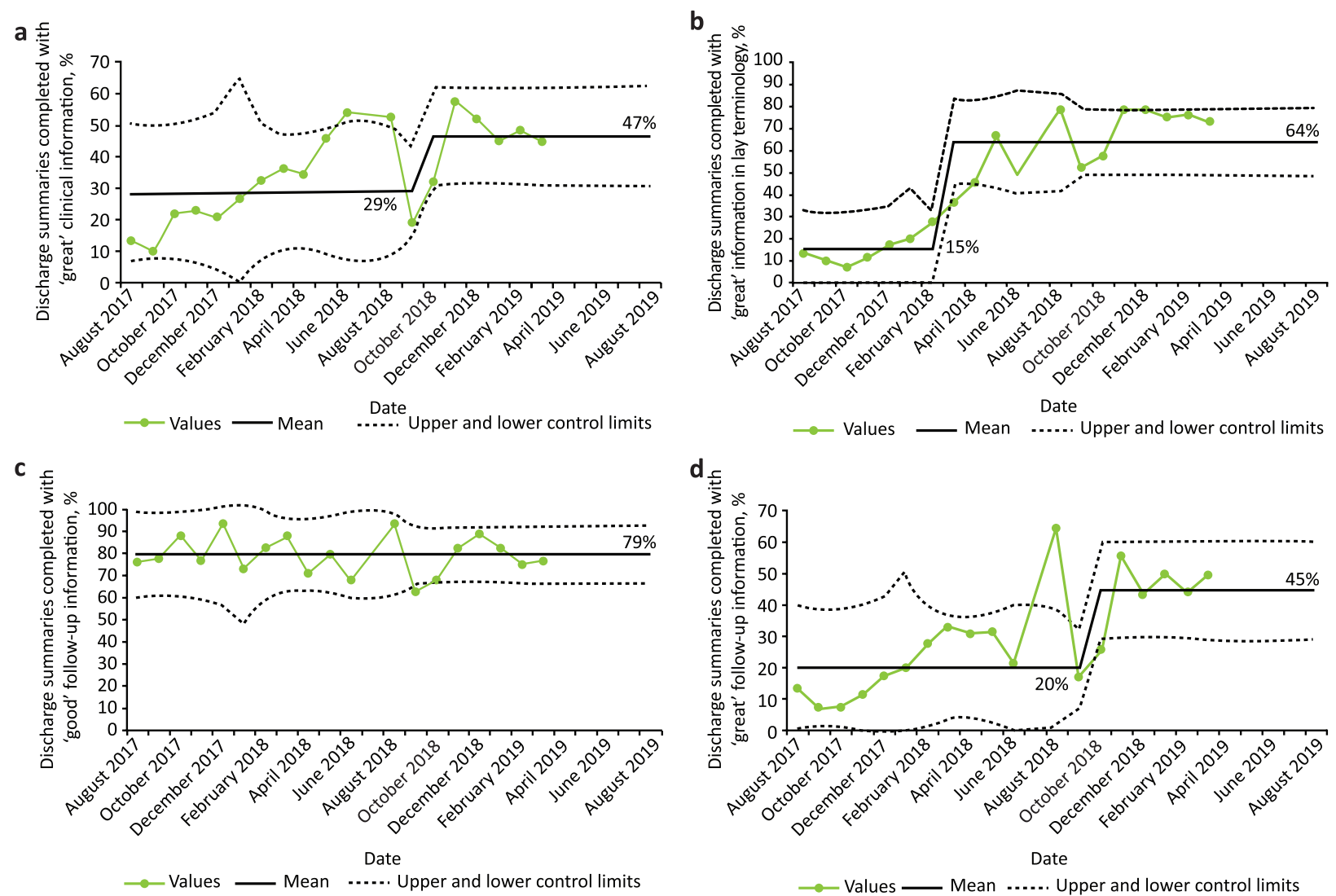

Fig 3. Impact of interventions on discharge summary quality. a) Accurate clinical summaries. b) Information given to patient in lay terminology. c) Information provided to the general practitioner at 'good' quality. d) Information provided to the general practitioner at 'great' quality.

For communication of follow-up actions to GPs, a relatively high baseline number of discharge summaries included information that was deemed of 'good quality, with most information present', and this percentage did not meaningfully improve over the course of the project (Fig 3c). However, Fig $3 \mathrm{~d}$ shows that the percentage of summaries completed to 'great quality, with all information present' increased following the interventions from a mean of $20 \%$ to $45 \%$.

The main challenge identified throughout the project was ensuring up-to-date data collection from the different clinical areas as junior clinicians, previously responsible for one area, moved onto a different rotation. This was overcome by having a senior registrar, in charge of data collection, who could obtain missing data. Due to the nature of the live feedback system, it was challenging to ensure reliable monthly dissemination of results, however good communication throughout the team and regular meetings ensured the poster-based feedback was provided on time.

\section{Discussion}

Improving discharge summaries clearly has an important role to play in improving the transition of patient care. A recent study showed reduced readmission rates following admission for heart failure exacerbations when discharge summaries included the recommended information. ${ }^{13}$ A separate study found improved prescription rates of denosumab following neck-of-femur fractures in patients when discharge summaries were improved. ${ }^{14} \mathrm{~A}$ further study showed increased patient satisfaction with their discharge summaries when a concerted effort to improve post-tonsillectomy summaries was made. ${ }^{15}$ Our study has therefore attempted to initiate a comprehensive series of changes in our discharge summaries, and has succeeded in improving the number of discharge summaries completed to a high standard.

Several key areas, such as the inclusion of required follow-up actions for GPs, have seen improvements in quality from 'good' to 'great'. Importantly, therefore, the data suggest that the interventions have increased the overall quality of information included within each discharge summary, rather than simply increasing the overall volume of information itself.

A drop in the overall quality of discharge summaries was noted on the rotation of each new cohort of junior clinicians to their new clinical area (specifically correlating to the months of December 2017, April 2018, August 2018 and December 2018; Fig 2). This phenomenon likely represents new junior doctors adapting to their new work environment. Importantly, the overall improvement in the quality of discharge documentation (as illustrated by the peaks of the graph) in the months immediately following junior doctor rotation increased as the project progressed. This suggests that the large-scale project was an increasingly effective operation, and that each subsequent cohort of clinicians was better educated and trained at completing discharge 
documentation compared to previous cohorts. Additionally, the greatest improvements were identified on wards where there is strong clinical engagement at consultant level to support training and engagement in the project. This suggests support from senior clinicians is important to maintain the improvements made by the project, especially given the frequency with which junior clinicians rotate jobs.

Dedicated training in how to prepare discharge documentation is very rare. Previous studies have shown that junior clinicians feel that specific training in discharge documentation would be of benefit. ${ }^{16}$ Therefore, there have been numerous previous attempts to carry out projects that aim to improve the quality of discharge summaries. ${ }^{17,18}$ Techniques employed have ranged from the provision of one-off and regular teaching sessions to clinicians through to programmes providing both teaching and feedback. ${ }^{19-23}$ Importantly, it has been shown that the results of these QIPs can be long-lasting. ${ }^{24}$ Additionally, the Royal College of Physicians has provided guidance on how to improve discharge summaries, which can be utilised when designing teaching on this subject. $^{25}$

The baseline quality of discharge summaries did not increase meaningfully on junior doctor rotation (in the months December 2017, April 2018, August 2018 and December 2018; Fig 2). This suggests that the project did not achieve year-wide dissemination of education regarding discharge documentation. In order to improve this baseline, further year-wide teaching strategies or engagement with junior clinicians earlier in their careers, possibly as medical students, may be required. Medical student education about discharge documentation was recently investigated. ${ }^{26}$ This study found that students felt more prepared and confident in their abilities to write discharge summaries, and that they would alter the way they write discharge summaries when they graduated. To expand on this, a PDSA-designed survey completed by junior doctors at induction found that a minority had any formal discharge summary teaching and felt that teaching would be of benefit to them. As a result, a 60-minute session was planned for new junior clinicians at the next induction, along with a 30-minute follow-up planned 4 weeks later.

Another possible mechanism to further improve the quality of summaries is to allow other professions to complete the relevant sections of the summary. For example, occupational therapists, physiotherapists, and speech and language therapists are in a strong position to document the functional assessments of patients. Ward-based pharmacists can identify what medication changes have been made during the inpatient stay. A recent study showed pharmacists' involvement in preparing discharge summaries can facilitate earlier discharge. ${ }^{27}$ Accordingly, pharmacists in our trust are starting to annotate the medication section of the discharge summaries.

Many hospitals, including our own, now use entirely electronic patient record systems. This has the potential to provide advantages in the completion of discharge summaries by allowing the pre-population of summaries with information pulled directly from the patient notes. A prior study found, when comparing paper with electronic discharge summaries, that electronic summaries were more likely to contain correct information regarding medication changes. ${ }^{28}$ Care would, of course, need to be taken to ensure this is done correctly, with the most up-to-date documentation included, and to ensure no subsequent changes are missed.
As well as providing benefits to primary care practitioners, high-quality discharge documentation is of direct benefit to patients. ${ }^{29}$ In an analysis of attendances vs non-attendances at follow-up appointments, it was found that if an appointment time was included within the discharge summary, patients were far more likely to attend their appointment than if there was no time included. ${ }^{30}$ Information included in lay terminology was a key focus of this quality improvement project, and significant improvements were observed. Feedback from patients and carers on this change has been overwhelmingly positive. However, this particular section sits at the end of the summary, and the possibility of bringing it to the front of the patient-facing version of the discharge summary is being explored. Additionally, expanding the use of lay terminology within other sections of the summary is being considered, with the goal of further improving accessibility to the patient, and potentially reducing confusion around medical terminology or acronyms that the reader may not be familiar with.

Methodological limitations of the study include that, due to the volume of summaries being reviewed, different clinicians were scoring discharge summaries from different clinical areas, potentially leading to inconsistencies in scoring. However, there was an appointed team lead, acting clinically at registrar level, who collated the summaries from the different areas each month. The team lead analysed a random set of 10 summaries per month to ensure consistency in scoring remained throughout the project. Additionally, the team lead would induct the clinicians who analysed discharge summaries in different clinical areas, so they knew the benchmark for a summary being rated as 'good' or 'great'. A further limitation is that we were unable to engage patients and other multidisciplinary team members during the RIE when designing the data collection tool. To mitigate this, we surveyed patients and staff members after design of the tool.

\section{Conclusion}

We identified several areas that are not being included adequately in discharge documentation, as recommended by national guidelines and deemed important by local practitioners. We designed a novel live-feedback PDSA model, performed monthly, which has demonstrated improvement in the quality of this documentation. This project will be continued with the aim of further improving the quality of the documentation, and with the aim of rolling this out to other health care services in the local area to improve patient care across the wider region.

\section{Funding}

Dr Earnshaw is funded by a National Institute for Health Research Academic Clinical Fellowship.

\section{References}

1 Academy of Medical Royal Colleges. Standards for the clinical structure and content of patient records. AoMRC, 2013. www. aomrc.org.uk/wp-content/uploads/2016/05/Standards_for_the_ Clinical_Structure_and_Content_of_Patient_Records_0713.pdf [Accessed 08 July 2019].

2 Darragh PJ, Bodley T, Orchanian-Cheff A et al. A systematic review of interventions to follow-up test results pending at discharge. J Gen Intern Med 2018;33:750-8.

3 Rochoy M, Gautier S, Béné J, Bordet R, Chazard E. Evolution of dementia related to the use of alcohol in the French nationwide 
discharge summary database between 2007 and 2017. Am J Alzheimers Dis Other Demen 2019;34:188-92.

4 Rochoy M, Chazard E, Gautier S, Bordet R. Vascular dementia encoding in the French nationwide discharge summary database (PMSI): Variability over the 2007-2017 period. Ann Cardiol Angeiol (Paris) 2019;68:150-4.

5 Preissner S, Siramshetty VB, Dunkel M et al. Pain-prescription differences-an analysis of 500,000 discharge summaries. Curr Drug Res Rev 2019;11:58-66.

6 Caleres G, Bondesson Å, Midlöv P, Modig S. Elderly at risk in care transitions When discharge summaries are poorly transferred and used-a descriptive study. BMC Health Serv Res 2018;18:770.

7 Garcia BH, Djønne BS, Skjold F, Mellingen EM, Aag TI. Quality of medication information in discharge summaries from hospitals: an audit of electronic patient records. Int J Clin Pharm 2017;39: 1331-7.

8 Gandara E, Moniz TT, Ungar ] et al. Deficits in discharge documentation in patients transferred to rehabilitation facilities on anticoagulation: results of a systemwide evaluation. Jt Comm J Qual Patient Saf 2008;34:460-3.

9 Mudge AM, Shakhovskoy R, Karrasch A. Quality of transitions in older medical patients with frequent readmissions: opportunities for improvement. Eur J Intern Med 2013;24:779-83.

10 Institute for Healthcare Improvement Innovation. Going Lean in Health Care. IHI, 2005. www.ihi.org/resources/Pages/ IHIWhitePapers/GoingLeaninHealthCare.aspx [Accessed 08 ]uly 2019].

11 Williams EI, Fitton F. Factors affecting early unplanned readmission of elderly patients to hospital. BMJ 1988;297:784-7.

12 Witherington EM, Pirzada OM, Avery AJ. Communication gaps and readmissions to hospital for patients aged 75 years and older: observational study. Qual Saf Health Care 2008;17:71-5.

13 Salim Al-Damluji M, Dzara K, Hodshon B et al. Association of discharge summary quality with readmission risk for patients hospitalized with heart failure exacerbation. Circ Cardiovasc Qual Outcomes 2015;8:109-11.

14 Wood H, Lewis H, Ward R, Solanki T, Fernando P. Improving community prescribing of post-fracture denosumab after discharge. $\mathrm{Br}$ J Hosp Med (Lond) 2017;78:20-2.

15 Carter A, Warner E, Roberton A et al. Tonsillectomy discharge information-An improvement in both patient safety and satisfaction. BMJ Open Quality 2014;2:u203433-w1546.

16 Otto M, Sterling M, Siegler E, Eiss B. Assessing origins of quality gaps in discharge summaries: a survey of resident physician attitudes. J Biomed Educ 2015;2015:341759.

17 Unnewehr M, Schaaf B, Marev R, Fitch J, Friederichs H. Optimizing the quality of hospital discharge summaries-a systematic review and practical tools. Postgrad Med 2015;127:630-9.

18 Hesselink G, Schoonhoven L, Barach P et al. Improving patient handovers from hospital to primary care. Ann Intern Med 2012;157:417-28.
19 Otokiti A, Sideeg A, Ward P et al. A quality improvement intervention to enhance performance and perceived confidence of new internal medicine residents. J Community Hosp Intern Med Perspect 2018;8:182-6.

20 Talwalkar JS, Ouellette JR, Alston S et al. A structured workshop to improve the quality of resident discharge summaries. J Grad Med Educ 2012;4:87-91.

21 Axon RN, Penney FT, Kyle TR et al. A hospital discharge summary quality improvement program featuring individual and team-based feedback and academic detailing. Am J Med Sci 2014;347:472-7.

22 Singh G, Harvey R, Dyne A, Said A, Scott I. Hospital discharge summary scorecard: a quality improvement tool used in a tertiary hospital general medicine service. Intern Med J 2015;45:1302-5.

23 Tan B, Mulo B, Skinner M. Discharge documentation improvement project: a pilot study. Intern Med J 2015;45:1280-5.

24 Bischoff K, Goel A, Hollander H, Ranji SR, Mourad M. The Housestaff Incentive Program: improving the timeliness and quality of discharge summaries by engaging residents in quality improvement. BMJ Qual Saf 2013:22:768-74.

25 Royal College of Physicians Health Informatics Unit. Improving Discharge Summaries - Learning Resource Materials. London: RCP, 2019. www.rcplondon.ac.uk/guidelines-policy/improving-dischargesummaries-learning-resource-materials [Accessed 02 ]anuary 2020].

26 Ming D, Zietlow K, Song Y, Lee H], Clay A. Discharge summary training curriculum: a novel approach to training medical students how to write effective discharge summaries. Clin Teach 2019;16:507-12.

27 Biggs MJ, Biggs TC. Independent prescribing pharmacists supporting the early discharge of patients through completion of medical discharge summaries. J Pharm Pract 2020;33:173-5.

28 Lehnbom EC, Raban MZ, Walter SR, Richardson K, Westbrook JI. Do electronic discharge summaries contain more complete medication information? A retrospective analysis of paper versus electronic discharge summaries. Health Inf Manag 2014:43:4-12.

29 National Institute for Health and Care Excellence. Transition between inpatient hospital settings and community or care home settings for adults with social care needs: NICE guideline [NG27]. NICE, 2015. www.nice.org.uk/guidance/ng27 [Accessed 08 July 2019].

30 Lam K, Abrams HB, Matelski J, Okrainec K. Factors associated with attendance at primary care appointments after discharge from hospital: a retrospective cohort study. CMAJ Open 2018;6:E587.

Address for correspondence: Dr Arturo Vilches-Moraga, Department of Ageing and Complex Medicine, Salford Royal Hospital NHS Foundation Trust, Stott Lane, Salford, M6 8HD, UK.

Email: arturo.vilches-moraga@srft.nhs.uk 